\title{
LA "DOMUS" DE SANTA LEOCADIA DE GUILLADE (PONTEAREAS) EN UN DOCUMENTO DEL AÑO 963. ESTUDIO SOBRE SU AUTENTICIDAD
}

\section{THE SANTA LEOCADIA OF GUILLADE "DOMUS" (PONTEAREAS) IN A 963'S PARCHMENT. A STUDY ABOUT ITS AUTHENTICITY}

\author{
MIGUEL ROMANÍ MARTÍNEZ1 \\ Universidad de Santiago
}

\author{
PABLO S. OTERO PIÑEYRO MASEDA ${ }^{2}$ \\ Instituto de Estudios Gallegos "Padre Sarmiento"
}

\begin{abstract}
Resumen
Se edita, analiza y contextualiza el documento más antiguo del fondo de Santa María de Melón del AHN, datado en la segunda mitad del siglo X. Tal documento se refiere a la fundación de la denominada "domus Sancta Leocadia" por los "homines" de Guillade, en el actual municipio pontevedrés de Ponteareas.
\end{abstract}

\section{Palabras clave}

Paleografía, Diplomática, Historia de la Iglesia, Edad Media, Monasterios, Císter, Galicia, Santa María de Melón

\section{Abstract}

The oldest document from Saint Mary of Melon's records, dated in the ${ }^{2 n d}$ half of the X century is here edited, analyzed and contextualized. Such document refers to the foundation of the so-called "domus Sancta Leocadia" by the "homines of Guillade", in the now municipality of Ponteareas (Pontevedra).

\section{Keywords}

Paleography, Diplomatic, History of the Catholic Church, Middle Ages, Monasteries, Císter, Galicia, Saint Mary of Melon

Entregado el 15/05/2009

1 Profesor Titular del Área de Ciencias y Técnicas Historiográficas del Dpto. de Historia I de la Universidad de Santiago. Este artículo es parte de los resultados del Proyecto "Documentación medieval del obispado de Ourense: edición y estudios", cuyo investigador principal es Miguel Romaní Martínez, subvencionado por MEC, Subdirección General de Investigación, Ref. HUM2004-05342.

2 Iste artigo foi preparado ó abeiro do Programa de recursos humanos (RHS) do Plan Galego de Investigación, Desenvolvemento e Innovación Tecnolóxica-Incite (2006-2010), Programa "Ángeles Alvariño", convocatoria 2008, cofinanciado polo Fondo Social Europeo. 
El rico fondo documental del monasterio orensano de Santa María de Melón permanece todavía inédito, lo que supone una gran frustración, pues sus importantes escrituras todavía no han rendido el fruto debido; por otra parte, muchos de los estudios hechos sobre la documentación de Melón siguen inéditos. ${ }^{3}$ Esta situación, lejos de ser singular, constituye, por desgracia, una generalidad penosa en la historiografía gallega ${ }^{4}$. Y todavía asombra comprobar cómo la edición de fuentes sigue

${ }^{3}$ El monasterio de Santa María de Melón ha sido tratado en numerosos estudios y monografías. No es aquí el lugar de referir todos ellos, pero sí conviene destacar algunos, especialmente los que valoran su riqueza documental: el polígrafo César VAAMONDE LORES publicó en la primera década del siglo XX un "Indice de documentos que pertenecieron al Monasterio de Melón", Boletín de la Real Academia Gallega, 1, núm. 6 (1906), 61-63; 1, núm. 4 (1906), 91-92; 1, núm. 5 (1906), 117; 1, núm. 6-7 (1906), 164-165; 1, núm. 8 (1906), 184-187; Año 2, vol. 1, núm. 9 (1907), 212-215; 1, núm. 10 (1907), 232-236; 1, núm. 11 (1907), 253-258. Pocos años después, fue objeto de un pequeño y desconocido estudio que le dio relevancia internacional por la prestigiosa institución americana "Archaeological Institute of America": véase Georgiana GoDDARD KING, "Saint Mary of Melón", American Journal of Archaeology, 21, núm. 4 (octubre-diciembre.1917), 387-396, disponible en < http://www.jstor.org/stable/497325 >. La primera tesis que trató este monasterio fue la de Segundo CAmbón SuÁrez, El monasterio de Santa María de Melón (siglos XII-XIII), Tesis Doctoral inédita, Santiago de Compostela, 1958. Dos memorias de licenciatura inéditas, casi cincuenta años después, se ocuparon de la transcripción de parte de los documentos melonenses custodiados en el Archivo Catedralicio de Orense: María José Losada Meléndez, La Documentación del Monasterio de Santa María de Melón del Archivo de la Catedral de Orense (ss. XII-XIII), Memoria de Licenciatura inédita, Santiago, Universidad de Santiago, Facultad de Xeografía e Historia, 1992 y María Teresa Sото Lamas, La Documentación del Monasterio de Santa María de Melón del Archivo de la Catedral de Orense (s. XIV), Memoria de Licenciatura inédita, Santiago, Universidad de Santiago, Facultad de Xeografía e Historia, 1992. Algunos documentos del fondo de Santa María de Melón fueron puntualmente transcritos: entre otros, véase Eladio Leirós, "Algunos privilegios pontificios al Monasterio de Melón”, El Museo de Pontevedra, 6 (1951), págs. 54-60; Alejandro Bugallo Álvarez, El Derecho patrimonial a través de los diplomas del Monasterio de Santa María de Melón, desde su fundación hasta el año 1282, Madrid, Universidad Pontificia de Comillas, Facultad de Derecho Canónico, 1968; Josefina JimÉnez Julí́, Reformas de explotación del dominio del Monasterio de Santa María de Melón, (1225-1275), Memoria de Licenciatura inédita, Santiago, Universidad de Santiago de Compostela, Facultad de Filosofía y Letras, 1973; M. ${ }^{a}$ del Carmen Pallares Méndez y Ermelindo PorTeLA SILVA, El bajo del Miño en los siglos XII y XIII: economia agraria y estructura social, Santiago de Compostela, Universidad, 1971; María Luz Ríos RodRíGuEz, "El Cultivo del cereal en Santa María de Melón (S.XII-XIV)" en II Congreso Internacional sobre el Císter en Galicia y Portugal: actas, [s.l., s.n.], d.l. 1999, vol. 2, 749-776; y Miguel Romaní Martínez y Pablo S. Otero PiñeYro Maseda, "Pergaminos irienses en los fondos de Oseira y Melón del AHN (siglos XI-XII). Estudio y edición", Gallaecia, 26, (2007), 347-363. Un magnífico estudio monográfico sobre el monasterio en el siglo $\mathrm{XV}$, pero sin edición documental, es obra del profesor orensano Francisco Javier PÉREZ RodRíGUEZ, $O$ mosteiro de Melón no século XV, Ourense, Deputación Provincial de Ourense, 1996 (2. a ed. en 2007).

${ }^{4}$ Con suma claridad expresó idéntica situación en el país vecino el profesor portugués Oliveira Marques: "Posteriormente aos «Portugaliae Monumenta Historica», poucas têm sido as colecções sistemáticas de documentos publicados em terra portuguesa, para vergonha das autoridades culturais e não menos dos eruditos amadores": véase António Henrique de OliveIRa MARQues, Guia do estudante de História Medieval portuguesa, $3^{a}$ ed., Lisboa, ed. Estampa, 1988 (Imprensa Universitária, num. 15), pág. 167. 
generando indiferencia entre círculos académicos presuntamente "renovadores" de la denominada "historia tradicional", practicando una "historia" pretendidamente innovadora que bajo títulos ampulosos generalmente poco aporta a la comprensión del pasado ${ }^{5}$. Al contrario, las nuevas herramientas informáticas -digitalizaciones, internet, software de tratamiento de imágenes, formato de almacenamiento de documentos...- posibilitan una nueva era en la edición de fuentes en particular y en las Ciencias y Técnicas Historiográficas en general, en suma, una verdadera renovación historiográfica de mano de la tecnología.

Así pues, en estas páginas se pretende contribuir a tal desarrollo, dando a conocer el documento más antiguo del fondo de Santa María de Melón, datado en la segunda mitad del siglo $X$. En él se refiere la minuciosa fundación de la denominada "domus Sancta Leocadia" por los "homines" de Guillade, que bien podría ser un pretendido cenobio, "casa" o "iglesia" en el entorno del actual municipio de Ponteareas, provincia de Pontevedra. Históricamente, su inicio pudo haber sido paralelo al de otras dos iglesias o pequeños monasterios como los de Santa María de Bárcena y San Miguel de Canales, absorbidos posteriormente estos por Santa María de Melón 6.

${ }^{5}$ El mismo profesor Oliveira Marques señalaba que "o marxismo de pacotilha que impregnava professores e alunos de História tanto despois como já antes do 25 de Abril (...) rejeitava de todo ou franzia o sobrolho a investigações demoradas com base documental que pouco adiantavam ás «leis» e às «verdades» já conhecidas. Para escrever sobre lutas de classe ou acumulação de capital não era muito preciso ir catar nos arquivos (...). Disto, houve e contínua a haver muito em Portugal, como em outros países. (...). É a mais perfeita esterilidade que se possa conceber no avanço do conhecimento. Esterilidade perigosa, contudo, porque oculta sob véus «progressistas» e pretensamente inovadores. E perigosa ainda porque assente em mentiras grandíloquas e bem soantes, afirmadas com desplante ou convicção": véase $i d . i b .$, pág. 242.

${ }^{6}$ La documentación relativa a los orígenes del monasterio de Santa María de Melón resulta problemática y controvertida, especialmente en su relación con los monasterios de Santa María de Bárcena (Barcia. Santa María de Quins. Municipio de Melón. Orense) y de San Miguel de Canales (Santo Estevo de Cans. Municipio de O Porriño. Pontevedra): véase su edición en Miguel Romaní Martínez y Pablo S. Otero Piñeyro Maseda, "Documentación relativa al principio del monasterio de Melón y sus relaciones con los monasterios de Bárcena y Canales: corpus documental", Galicia Monástica. Estudos en lembranza da profesora María José Portela Silva, Santiago, Universidade de Santiago de Compostela, 2009, 23-37. El profesor Francisco Javier Pérez Rodríguez ha repasado recientemente las diferentes teorías respecto a los orígenes de Melón, tomando parte por la propuesta de José Freire Camaniel, es decir, una comunidad monástica con dos cenobios, ocupándose el de Barcia, el más antiguo, mientras no se remataba de construir el de Melón: véase Francisco Javier Pérez RodRíGuez, Mosteiros de Galicia na Idade Media (séculos XII-XV). Guía histórica, Ourense, Deputación Provincial de Ourense; Fundación Caixa Galicia, 2008, págs. 192-195. 


\section{ANÁLISIS DEL DOCUMENTO}

\section{Descripción y conservación}

El documento que ahora se edita pertenece al Archivo Histórico Nacional, sección Clero, fondo de pergaminos del monasterio cisterciense de Santa María de Melón (Melón. Orense). Es el primero de esta serie, y se conserva en la carpeta 1437, siendo el pergamino número 1 de la citada carpeta (fig. 1).

Se trata de un pergamino de generosas medidas: $555 \mathrm{~mm}$. de largo por $320 \mathrm{~mm}$. de alto. En el sentido de la máxima dimensión presenta tres dobleces verticales proporcionalmente repartidas; otra doblez lo recorre horizontalmente por el centro cortando las dobleces verticales. La doblez horizontal, muy desgastada, se ha roto en la mitad derecha del anverso, estando cosida actualmente con un precario hilo. Lo mismo ocurre en la la mitad superior del plegado central, remendada con otro hilo.

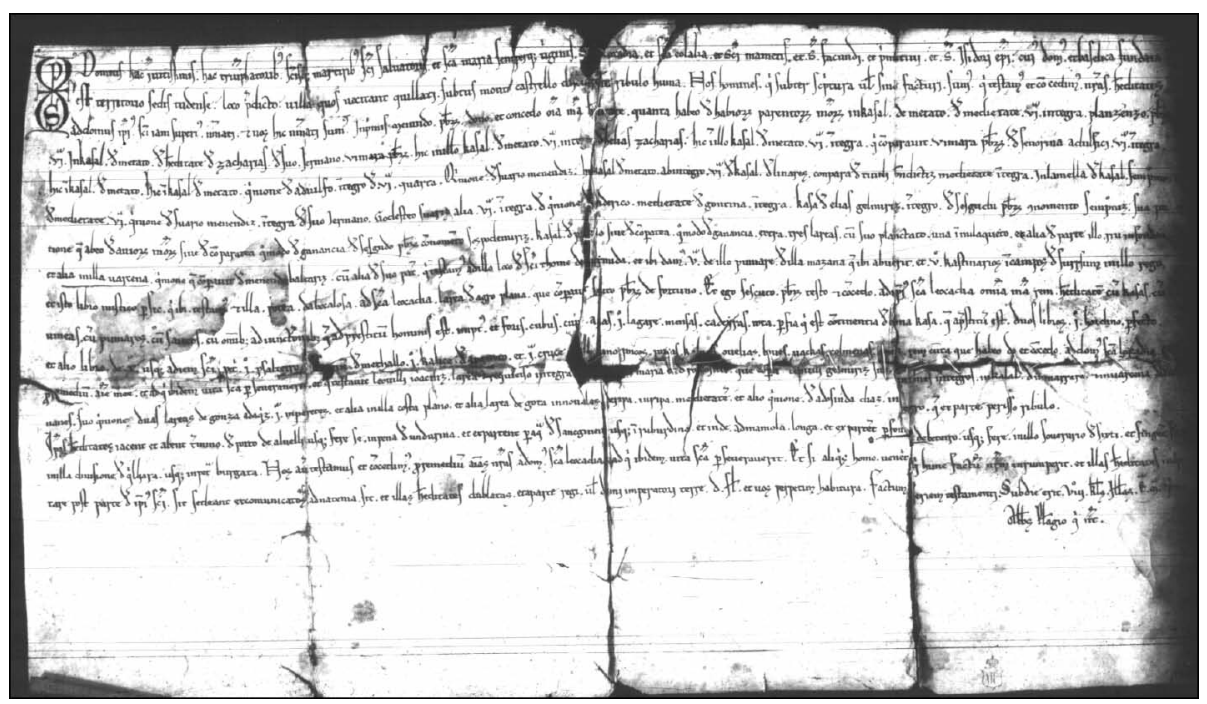

Figura 1

Todas estas marcas evidencian la práctica habitual del plegado en pergaminos grandes, tanto medievales como modernos. En suma, para proteger el texto de agresiones exteriores, se toma el pergamino con el anverso de cara a la persona que lo maneja, se dobla por la mitad tomando como eje la parte más corta; se pliega otra vez sobre el mismo eje, y seguidamente se dobla sobre el eje más corto. De esta forma, las marcas que provoca el plegado acabarán compartimentando el espacio escriptorio en ocho rectángulos. El paso del tiempo hace que el pergamino pierda 
flexibilidad; a causa de ello las dobleces de fuera se rompen y en algún momento serán rusticamente cosidas; ocasionalmente, las esquinas exteriores sufrirán los mordiscos de algún ratón de archivo.

Este es el aspecto que presenta el pergamino que ahora se estudia. La fortuna ha querido que el texto no haya sido inhabilitado más que en muy pequeñas partes.

\section{Cronología y aspectos paleográficos}

El documento, que es otorgado por los "hombres" de Guillade a la iglesia de Santa Leocadia, se fecha en la Era $M^{a} \cdot p^{i} m a=1001$; es decir, en el año 963. Su escritura, por tanto, debería corresponderse con la visigótica cursiva; sin embargo, el texto del pergamino se escribe con minúscula diplomática.

Según el profesor Lucas Álvarez las manifestaciones del ciclo carolino en la escritura documental se producen en los reinos occidentales durante la segunda mitad del siglo XII, entre otras, mediante las variantes de la llamada minúscula diplomática ${ }^{7}$. Por tanto, no cabe sino pensar que el documento que se edita es una copia. Siguiendo al mismo profesor, la minúscula diplomática

es una letra esbelta, de astiles y caídos largos y curvados; letra «d» con frecuencia de tipo uncial ligeramente recurvada; letras aisladas y exentas de nexos; hay una ligera tendencia a la movilidad de los astiles a medida que avanza el período; letra «g» muy generosa en la curvatura de su parte inferior; tendencia generalizada a incrementar la fractura interna del cuerpo de las letras y abreviaturas muy frecuentes pero comunes en el período ${ }^{8}$.

Las características descritas coinciden absolutamente con la escritura del pergamino objeto de estudio (fig. 2). Pero, todavía puede precisarse más.

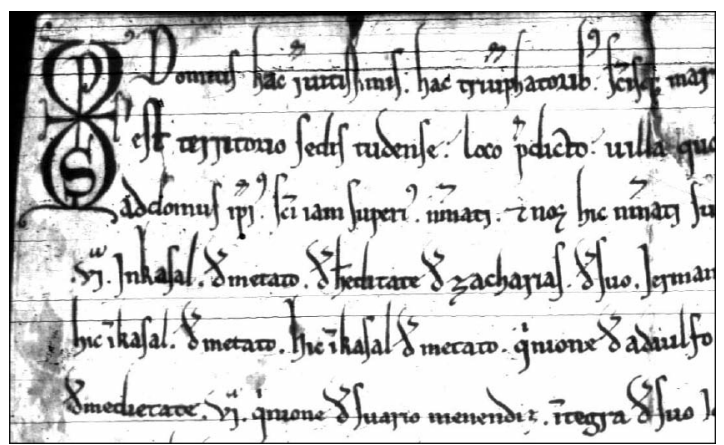

Figura 2

7 Véase Manuel Lucas Álvarez, "Paleografía gallega. Estado de la cuestión", Anuario de Estudios Medievales, 21 (1991), pág. 450.

${ }^{8} I d . i b$. 
Sin duda alguna, el amanuense que hizo la copia tomó como modelo algún documento real de la cancillería de Fernando II (1157-1188). A efectos de comprobación, un privilegio concedido a Melón por el referido monarca ${ }^{9}$ permite compararlo con el documento de "los hombres de Guillade", observándose que el parecido estilístico-paleográfico entre ambos salta a la vista: los dos muestran, en palabras del profesor Floriano Cumbreño sobre los diplomas de Fernando II, "una letra redonda, sentada, sin grandes primores caligráficos, pero bella"; dentro de este modelo el autor observa, según los amanuenses, algunas variantes más cursivas de formas angulosas; asimismo, establecece que entre ambas variedades pueden escalonarse algunas que son "evidentemente redondas con tendencia a la cursividad"10, y cita -entre otros que practican esta última variante- los diplomas de Pelayo Gutiérrez, el cual es, precisamente, el autor gráfico del citado documento de Fernando II, cuyas características coinciden plenamente con el documento objeto del presente estudio (fig. 3).

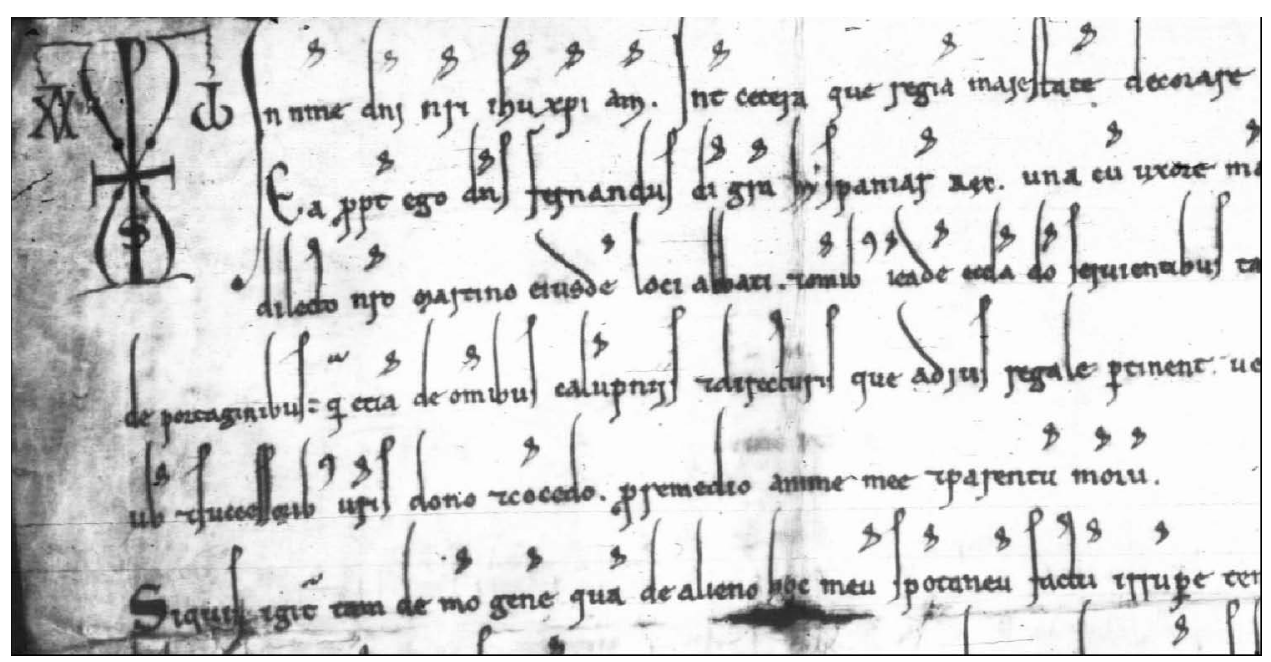

Figura 3

Así pues, el copista que transcribió el documento originalmente visigótico de "los hombres de Guillade" no tuvo demasiadas dificultades para encontrar en el

\footnotetext{
${ }^{9}$ Documento otorgado por el rey Fernando II datado en Salamanca, 2 de noviembre de 1172: véase AHN, Clero, carpeta 1438, núm. 7.

${ }^{10}$ Véase Antonio Floriano Cumbreño, Curso general de paleografía y paleografía y diplomática españolas: (con un apéndice de diplomática pontificia). Texto, Oviedo, Imprenta "La Cruz", 1946, págs. 438-439.
} 
archivo de Melón un modelo gráfico que se ajustase mejor a una escritura más clara y legible. La copia se realizó seguramente durante el reinado de Fernando II (11571188), o poco después.

Los autores de estas líneas están convencidos de la fecha en que se hizo la copia, porque durante los siglos XII y XIII en el reverso de los documentos de Melón y Oseira suele escribirse con letra coetánea una breve frase alusiva al contenido del pergamino; en este caso la frase es "Testamentum de sancta leocadia de ripateuea"11 (fig. 4), cuya letra, sin poder asegurar que sea de la misma mano del copista, sí se puede decir que es coétanea del momento en que se transcribió la copia; en todo caso, pudiera alegarse en favor de la autoría del copista que éste no creería necesario escribir dicha frase en el reverso con una letra tan solemne como la del documento acabado de copiar.

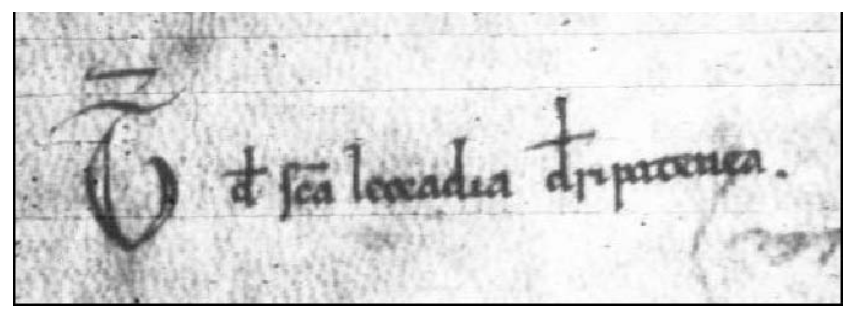

Figura 4

A la pregunta sobre las razones que originaron la copia, sólo pueden aportarse conjeturas: la antigüedad del documento, su posible mala conservación, la dificultad de su lectura, o bien que se estimase como muy valioso su contenido por el hecho de que el documento original de donación pudiera haber sido escrito en el "libro místico" que se dona a la iglesia de Santa Leocadia ${ }^{12}$. Sea como fuere, el copista - del cual debe elogiarse su gran pericia caligráfica- eligió en el archivo monástico el modelo que le inspiró más respeto y solemnidad: un privilegio concedido a Melón por Fernando II. Era lo mejor y lo más estético en aquel momento.

\section{Redacción y estudio diplomático}

Aceptado que se trata de una copia y establecido el momento en que esta de efectuó, corresponde averiguar si la redacción y formulación diplomática es fidedigna, es decir, si se corresponde con los usos habituales del siglo $\mathrm{X}$.

${ }^{11}$ Las letras abreviadas se restituyen en cursiva.

12 Véase texto referido a las ns. 16 y 17. 
En general, la redacción resulta creíble. Responde a un documento redactado por un amanuense rural no muy versado y desprovisto de cualquier refinamiento. El latín utilizado es tosco, la parte dispositiva resulta confusa, abundan las concordancias incorrectas, y la ortografía es anárquica. Por otra parte, la presencia mayoritaria de nombres de persona y apellidos de estirpe germánica, acreditan la verosimilitud de su fecha. Entre las personas que figuran como donantes en el documento hay cinco presbíteros, a los cuales debe añadirse el amanuense que, sin duda, sería también religioso. Se supone que en las deliberaciones previas que condujeron a la conscriptio del documento, con el consenso de los otorgantes y con la asesoría de los presbíteros citados, se elaboraría una minuta o borrador; éstos últimos dictarían finalmente el mundum o documento definitivo al amanuense que suscribe.

El aparato diplomático, es decir, las diversos apartados que componen el documento, tampoco indican nada extraño.

La primera parte, el protocolo, comprende: invocación simbólica mediante el crismón que, en lugar del habitual signo cursivo y esquemático de la documentación visigótica, se traduce a su correspondiente de los diplomas de Fernando II; sigue una larga invocación adjetivando a diversos mártires y santos, al Salvador, a la Virgen Maria... y finalmente, las correspondientes referencias geográficas a la ubicación de los bienes donados, al territorio y a su jurisdicción episcopal.

A continuación la intitulación genérica de los otorgantes: "Nos, homines qui (...) sumus"; sigue el dispositivo verbal: "qui testamus et concedimus (...)"; intitulación del destinatario: "domus ipsius sancti iam superius nominati”, refiriéndose a la iglesia de Santa Leocadia, según se deduce en el dispositivo documental. Éste comienza con la relación de donantes y la aportación de cada uno de ellos.

La motivación: "pro animas nostras" figura después del dispositivo documental.

La parte final, o escatocolo, presenta las habituales cláusulas: de sanción, con penas espirituales de excomunión y anatema, y penas materiales: restitución en el doble a la parte agraviada, además de una multa de 500 sueldos, que el contraventor pagará a la autoridad establecida; concluye este apartado corroborando a perpetuidad el hecho documentado.

La datación: era hispánica, convirtiendo en este caso la I con guión sobrepuesto de la cifra visigótica mil en su equivalente carolino " $\mathrm{M}$ " " $\mathrm{y}$, en lugar de expresar "I", el amanuense opta por escribir "prima" con todas sus letras.

Finalmente, la suscripción del amanuense "(...) qui notuit”.

Reconociendo que el análisis diplomático parece el que habitualmente se utiliza en medios rurales durante el siglo X, no obstante, para mayor precisión, se decidió hacer una comparación con documentos de la misma época, es decir, entre el año 900 
y el 999. Para ello se utilizaron los tumbos gallegos de Celanova ${ }^{13}$, Sobrado ${ }^{14} \mathrm{y}$ Samos ${ }^{15}$, resultando este último el más abundante en documentos del siglo $\mathrm{X}$.

La finalidad era comprobar, especificamente, si el grupo de frases que corresponde a las invocaciones del inicio y las referencias espaciales que le siguen "ecclesia fundata in territorio...", etc. concuerdan con las expresiones de la época, ya que este conjunto conjunto es muy significativo dentro del tipo documental estudiado (tabla 1).

\begin{tabular}{|cc|cc|cc|cc|cc|}
\hline \multicolumn{10}{|c|}{ Tumbo DE SAMOs } \\
\hline Santa María & \multicolumn{2}{|c|}{ El Salvador } & \multicolumn{2}{|c|}{ Domnos Santos } & \multicolumn{2}{c|}{ Mártires } & \multicolumn{2}{c|}{$\begin{array}{c}\text { Basílica/ecclesia } \\
\text { Fundata }\end{array}$} \\
\hline Año & Núm. & Año & Núm. & Año & Núm. & Año & Núm. & Año & Núm. \\
\hline 951 & 93 & 902 & 33 & 931 & 119 & 938 & 43 & 922 & 37 \\
\hline 967 & 91 & 947 & 226 & 938 & 43 & 951 & 93 & 938 & 43 \\
\hline 981 & 181 & 973 & 217 & 951 & 93 & 958 & 127 & 951 & 93 \\
\hline & & & 958 & 127 & 962 & 32 & 958 & 127 \\
\hline & & & 960 & 248 & 963 & 175 & 960 & 248 \\
\hline & & & 967 & 91 & {$[976]$ post } & 29 & 970 & 102 \\
\hline & & & 969 & 158 & 978 & 132 & 973 & 175 \\
\hline & & & 973 & 175 & 981 & 181 & 973 & 217 \\
\hline & & & {$[976] p o s t$} & 29 & & & 978 & 132 \\
\hline & & & 978 & 132 & & & 981 & 27 \\
\hline & & & 981 & 181 & & & 982 & 153 \\
\hline & & & 981 & 27 & & & & \\
\hline & & & 982 & 23 & & & & \\
\hline & & & 982 & 153 & & & & \\
\hline
\end{tabular}

Tabla 1

13 Véase Emilio SÁEz y Carlos SÁEz, Colección diplomática del Monasterio de Celanova: (8421230), Alcalá de Henares, Universidad de Alcalá, Servicio de Publicaciones, 1996-2006 (Colección Galicia de la Universidad de Alcalá de Henares, núms. 1, 2 y 5) y José Miguel ANDRADE CERnAdAS (ed.), O Tombo de Celanova : estudio introductorio, edición e índices: (ss. IX-XII), Santiago de Compostela, Consello da Cultura Galega, 1995, 2 vols. (Colección Fontes documentais para a historia de Galicia).

${ }^{14}$ Véase Pilar Loscertales de G. De Valdeavellano, Tumbos del Monasterio de Sobrado de los Monjes, Madrid, Dirección General del Patrimonio Artístico y Cultural, Archivo Histórico Nacional, 1976, 2 vols. 


\begin{tabular}{|c|c|c|c|c|c|c|c|c|c|}
\hline & & & & Tuмво & Celan & & & & \\
\hline Santa & María & El Sa & vador & Domn & Santos & Má & tires & $\begin{array}{l}\text { Basílica/e } \\
\text { Fund }\end{array}$ & $\begin{array}{l}\text { cclesia } \\
\text { ata }\end{array}$ \\
\hline Añ̃o & Núm. & Año & Núm. & Año & Núm. & Año & Núm. & Año & Núm. \\
\hline [909] & 10 & 936 & 50 & 907 & 9 & [909] & 10 & [909] & 10 \\
\hline 927 & 27 & 941 & 65 & 927 & 27 & 927 & 27 & 927 & 27 \\
\hline 988 & 203 & [952] & 98 & 936 & 50 & 947 & 81 & 936 & 50 \\
\hline 988 & 204 & 953 & 101 & 952 & 95 & 988 & 203 & [934]-[938] & 59 \\
\hline & & 973 & 175 & 962 & 154 & & & 962 & 154 \\
\hline & & 985 & 197 & 972 & 174 & & & & \\
\hline & & 986 & 198 & 973 & 175 & & & & \\
\hline & & & & 988 & 203 & & & & \\
\hline & & & & TuMB & SOBRA & & & & \\
\hline Santa & María & EI Sa & vador & Domn & Santos & Má & tires & $\begin{array}{l}\text { Basílica/e } \\
\text { Fund }\end{array}$ & $\begin{array}{l}\text { cclesia } \\
\text { ata }\end{array}$ \\
\hline Año & Núm. & Año & Núm. & Año & Núm. & Año & Núm. & Año & Núm. \\
\hline 905 & 33 & 939 & 41 & 910 & 33 & 935 & 118 & 910 & 33 \\
\hline 935 & 118 & 955 & 2 & 922 & 120 & 955 & 2 & 939 & 41 \\
\hline 939 & 41 & 958 & 56 & & & 958 & 56 & 958 & 106 \\
\hline 968 & 13 & 961 & 7 & & & 961 & 7 & 964 & 36 \\
\hline 966 & 6 & 964 & 36 & & & 964 & 36 & 968 & 107 \\
\hline 985 & 38 & & & & & 966 & 6 & 992 & 130 \\
\hline
\end{tabular}

Continuación Tabla 1

A la vista de los resultados contenidos en el cuadro, se observa que las alusiones a los motivos expresados son de uso habitual en el siglo $\mathrm{X}$, precisando que las invocaciones y referencias espaciales hechas al principio del documento son características de documentos solemnes, cuyos otorgantes, en general, pertenecen a personas de relevancia, siendo este tipo documental muy distinto de aquellos, cuyos actores no exhiben caracterización estamental. Por tanto, los redactores del documento, dentro de sus posibilidades, quizá usaron algún rústico formulario, o bien copiaron como mejor pudieron tales cláusulas de algún documento solemne que tenían a su alcance. Lo que sí está claro es que quisieron darle al hecho documentado la relevancia debida. 
Por tanto, y a tenor de todo lo estudiado, el contenido del documento de los "hombres de Guillade" -dada su concordancia con otros similares y ante la ausencia de síntomas sospechosos de ninguna clase, pero con las reservas que en su momento se expondrán- puede considerarse totalmente fidedigno, a pesar de tratarse de una copia.

\section{La historiografía del documento: otros autores}

En primer lugar, debe mencionarse la edición hecha en el año 1952 a cargo de Jesús Ferro Couselo, tomada sobre un tumbo de Melón, el llamado "Tumbo de fray Lorenzo", datado en $1611^{16}$. La transcripción no difiere esencialmente de la que es objeto de este estudio. Habría que señalar que uno de los códices citados en el documento se transcribe "alio libro de $\mathrm{X}^{\mathrm{a}}$ " -tal como transcribe Ferro- cuando en la copia simple en pergamino figura " $\mathrm{X}^{\mathrm{L}}$," Por otra parte, el mismo autor expone al final de la transcripción

el romance, como puede verse por la construcción, aunque en una fase arcaica, estaba ya plenamente formado. El autor del documento desconocia casi del todo la construción latina, y se limita a traducir palabras aunque se deslizan sin alteración algunas del romance como «leira», «ovelias», «cadeiras», «undurina».

De ello se deduce que Ferro Couselo da por sentado que está ante la copia de un documento original del año 963, y afirma que el "romance" o gallego estaba ya "plenamente formado". Posiblemente no habría sido tan tajante, de haber conocido la copia en pergamino del Archivo Histórico Nacional sobre la cual se reproduce en los Tumbos de Melón el documento editado por Ferro Couselo.

La atribución de la categoría de monasterio a Santa Leocadia es repetida por Rubén García Álvarez -basándose en el edición de Ferro Couselo- años después ${ }^{17}$.

La misma atribución monástica hace el profesor Díaz y Díaz siguiendo a los dos autores citados anteriormente; por otra parte, precisa que el documento de donación a Santa Leocadia pudiera haber sido escrito originariamente en alguna página del "libro místico" que se cita en el documento ${ }^{18}$. De hecho, la frase "et isto libro mis-

\footnotetext{
15 Véase Manuel Lucas Álvarez, El Tumbo de San Julián de Samos (Siglos VIII-XII). Estudio introductorio edición diplomática apéndices e índices, Santiago de Compostela, Caixa Galicia, 1986 (Colección Publicaciones de la Obra Social Caixa Galicia).

${ }^{16}$ Véase Jesús FerRo COUSELO, Los petroglifos de término y las insculturas rupestres de Galicia, Orense, Talleres gráficos de Miguel López Elizalde, 1952, doc. 15, págs. 220-221.

17 Véase M. Rubén García Álvarez, "Los libros en la documentación gallega de la Alta Edad Media", Cuadernos de Estudios Gallegos, 20, fasc. 62 (1965), pág. 24.

${ }^{18}$ Véase Manuel C. DíAz y DíAz, Códices visigóticos en la monarquía leonesa, León, Centro de Estudios e Investigación San Isidoro, 1983 (Col. Fuentes y Estudios de Historia Leonesa, 31), pág. 168 y n. 55.
} 
tico per sic qui ibi testamus" -al principio de la novena línea-, sí que podría traducirse libremente como "y este libro místico en el cual escribimos esta donación...". Además, el profesor Díaz -siguiendo la edición de Ferro Couselo- aunque tampoco conoce la copia en pergamino, intuye que otro libro citado en el documento como "alio libro de $\mathrm{X}^{\mathrm{a}}$ " debería decir "alio libro de $\mathrm{X}^{\mathrm{L} \text { ", } 19}$.

Abundando en lo dicho, el profesor Lucas Álvarez, siguiendo a su vez al profesor Díaz y Díaz, admite tácitamente la veracidad del documento publicado por Ferro Couselo cuando lo incluye en la relación que hace de códices visigóticos gallegos $^{20}$. De hecho, los cuatro libros citados en este documento representan el $10 \%$ de las cuarenta menciones documentales galaicas que citan específicamente libros escritos con letra visigótica ${ }^{21}$.

Finalmente, el documento en pergamino parece verosímil en todos sus aspectos, si no fuera porque contiene una serie de "galleguismos" demasiado copiosa para encajar su texto en el año 963. Asimismo, la cantidad de tales "galleguismos" incluso podrían parecer un tanto precoces para los años finales del siglo XII, fecha estimada por los autores de estas páginas para datar la copia del hipotético pergamino original del año 963.

Sobre esta cuestión caben varias posibilidades:

-ya se expuso la calidad y cuidado que puso el amanuense monástico a la hora de elaborar la copia. Teniendo en cuenta sus habilidades y pericia gráfica, parece extraño que introdujese palabras romanceadas. Por tanto, puede pensarse que copió todo tal como lo halló.

-si el copista hubiera cometido una falsificación consciente, dado su conocimiento de los archivos, no se le ocurriría mezclar lenguas; con ello se vuelve a la posibilidad anterior. Es más, sería bastante fatigoso inventar un dispositivo documental tan complejo, como para hacer y concordar parentescos.

-en contra de las dos posibilidades ya expuestas, el amanuense vertería al gallego algunas palabras latinas por considerarlas impropias o difíciles ya de entender en su momento.

En todo caso, del estudio paleográfico se deduce que el documento en pergamino no pudo escribirse antes del reinado de Fernando II, ni mucho después de fines del siglo XII. Corresponde, pues, a los filólogos arrojar luz sobre las formas gallegas. Ellos tienen la última palabra sobre las que pudieran estar entre las primeras del gallego.

${ }^{19} \mathrm{Id}$. ib.

${ }^{20}$ Véase Manuel LuCAs Álvarez , "Paleografía gallega. Estado de la cuestión...”, pág. 431.

${ }^{21}$ Id ib., pág. 429. 


\section{Santa Leocadia: iglesia o monasterio}

En el regesto del documento que publica Ferro Couselo se dice "donación hecha en 963 al monasterio de Santa Leocadia de Guillade...". Esta afirmación no fue discutida, como se ha visto, por los otros autores; sin embargo, que Santa Leocadia sea un monasterio parece poco fundamentado, puesto que en el documento no se menciona explícitamente la palabra "monasterio" ni se habla tampoco de vida en común. A este respecto puede señalarse que el presbítero Sescuto expresa en el renglón 12 que efectúa su donación por remedio de su alma "et ad qui ibidem uita sancta perseruauerit", lo que puede traducirse por "y para que allí mismo la vida santa dure permanentemente", lo cual, como es obvio, alude a la conducta que debe observar el sacerdote que lleve la iglesia. Con respecto al amanuense que suscribe el documento como "Abbas Pelagius", la palabra abad -aparte de su significado como padre de una comunidad monástica- se ha usado en Galicia hasta casi nuestros días como sinómino de "cura de la parroquia", es decir, como padre o cabeza espiritual de la comunidad parroquial de vecinos; por ello, los autores de este estudio se inclinan por la idea de que Santa Locadia fue fundada como iglesia por los vecinos de la villa de Guillade para atender a sus necesidades espirituales y de alguna forma para consolidar la presencia de su comunidad en aquel territorio.

\section{Ubicación de la iglesia de Santa Leocadia}

La villa de Guillade, sede hoy de la iglesia parroquial de San Miguel de Guillade y a cuya jurisdicción pertenece actualmente el lugar de Santa Locaia, se localizaba en los siglos medievales en el entorno de una importante vía comercial que comunicaba el Bajo Miño y las tierras del Ribeiro de Avia. La profesora Elisa Ferreira sitúa a la ciudad episcopal de Tuy como "el principal nudo de comunicaciones de su parte Sur [se refiere al Bajo Miño]". Esta villa -siguiendo a la profesora Ferreira- se uniría con las tierras orensanas -además de por la "calzada romana que bordea el Miño hasta Tuy"- por "un camino que, procedente del Ribeiro, pasa por el Santuario de la Franqueira y por Puenteareas para terminar en Porriño", aunque el tramo de "Franqueira a Ponteareas está mal determinado en los documentos medievales" 22 : y es precisamente en el camino que une Franqueira con Ponteareas en donde se situa Guillade, si bien la importancia del camino parece ser mayor en los siglos posteriores al de la donación de los "hombres" de Guillade.

22 Véase Elisa Ferreira Priegue, Los caminos medievales de Galicia, Ourense, Museo Arqueolóxico Provincial, 1988 (Colección Boletín auriense. Anexo, 9), págs. 67, 73, 75 y 97. 
El lugar de Santa Locaia se sitúa al N. de la iglesia de San Miguel de Guillade, conservándose los restos de la que debió ser la antigua iglesia ${ }^{23}$. En 1981, Claudio González Pérez, basándose, una vez más, en la edición de Ferro Couselo, repite su carácter monástico; dice que el monasterio de Santa Leocadia

Estaba situado en el lugar de A Encostada, donde hace algunos años aparecieron al hacer unas excavaciones Juan Martínez de Tamuxe (de aquella párroco de Guillade), restos arquitectónicos, fragmentos de una pila bautismal, un canecillo etc. Se aprecian, según parece, ciertas influencias visigóticas en la disposición del edificio (del que tan solo restan los cimientos), que avalarían la hipótesis de que el origen de este cenobio hay que situarlo entre los siglos VI y VIII'.

El mismo autor señala que en 1528 aún existía la parroquia de Santa Leocadia de Guillade al constar en las "Constituciones Sinodales del Sínodo que celebró el Obispo de Tuy don Diego de Avellaneda" que tenía que pagar a la mesa episcopal "la Iglesia de Sta. Locaya (sic) de Guillade media libra de cera"25.

Por otro lado, las "excavaciones" emprendidas por Xoán Martínez do Tamuxe en torno a 1962 y 1976 en Guillade, tampoco confirman la existencia de tal monasterio: aunque localiza importantes restos de la ermita -en la zona de la Encostada-Vigaria-, las demás ruinas existentes en sus proximidades -que denomina "antiguo poblado""a nuestro juicio las consideramos más bien recientes y dedicadas a corrales, etc", si bien señala a continuación que Hipólito de Saa se inclina por definirlas como "divisiones de la vivienda de los varones retirados en aquella soledad. Estrechas y diminutas celdas comunicando con un pasillo común... en la casa monacal", sin duda guiado más por su celo monástico que por las evidencias materiales ${ }^{26}$.

${ }^{23}$ Los autores expresan su agradecimiento a don Antonio José Groba, archivero municipal de Ponteareas, por las informaciones y bibliografía facilitada para la elaboración de estas páginas.

24 "La primera cita documental [de Guillade] es del año 963, y se trata de una donación al monasterio de Santa Leocadia, que estuvo situado en el lugar de A Encostada, perteneciente a la desaparecida parroquia de Santa Leocadia de Guillade": véase Mariano PiñeIro GrobA, Claudio González PÉREZ, Historia de Puenteareas, Puenteareas, Centro Cultural Municipal, 1983, págs. 65-66 y 81-83. En realidad, este volumen comprende dos estudios distintos: el primero de ellos es una edición facsimilar de la obra de Mariano Piñeiro Groba, Puenteareas: datos históricos, notas y apuntes para el estudio de la etimología de los nombres de las parroquias, barrios y otros lugares del distrito, Puenteareas, [s.n.], 1941; el segundo, complemento de aquel, es de Claudio González Pérez, Aproximación a la historia de Ponteareas, de 1983.

${ }^{25} I d$. ib., págs. 65-66.

${ }^{26}$ Véase Xoán MartíneZ do TAMuXe, "Documento medieval. Pista arqueológica de un monasterio”, Tuy, Museo y Archivo Histórico Diocesano, 3 (1977), pág. 69. 


\section{La donación de los "hombres de Guillade"}

Podría ser una más entre las muchas que se producen en los siglos altomedievales: a ojos de hoy podría decirse que se trata de una "cooperativa rural" de los vecinos de dicha villa para fundar una iglesia, la domus de Santa Leocadia. Este hecho sería un indicio del auge demográfico que se producirá en los siglos posteriores.

Entre todos aportan los bienes necesarios para el sostenimiento del correspondiente clérigo y el ajuar litúrgico necesario para que éste desempeñe sus funciones. Los bienes donados para el sostenimiento de la misma deberían estar próximos a la iglesia, pero su localización actual parece poco menos que imposible.

En la tabla que sigue se expone la relación de las personas citadas en el documento, numerándose según el orden por el cual se mencionan en el pergamino, haciendo referencia a sus posibles parentescos y a otras circunstancias.

\begin{tabular}{|c|c|c|}
\hline 1.- Menindo, presbiter. & 2.- Planzenzo, presbiter. & $\begin{array}{l}\text { 3.- Zacharias, hermano de } \\
\text { Vimara presbiter (4) padre de } \\
\text { (5). }\end{array}$ \\
\hline $\begin{array}{l}\text { 4.- Vimara presbiter, herma- } \\
\text { no de Zacharias (3). }\end{array}$ & $\begin{array}{l}\text { 5.- Helias Zacharias, hijo de } \\
\text { Zacharias (3), compró a } \\
\text { Vimara presbiter (4). }\end{array}$ & $\begin{array}{l}\text { 6.- Senorina Adaulfici, hija } \\
\text { de Adaulfo ( } 7) \text {. }\end{array}$ \\
\hline $\begin{array}{l}\text { 7.- Adaulfo, padre de Senori- } \\
\text { na Adaulfici (6). }\end{array}$ & $\begin{array}{l}\text { 8.- Suario Menendiz, padre } \\
\text { de Godesteo Suariz (11) }\end{array}$ & $\begin{array}{l}\text { 9.-Tiuili Benedictiz, vendió a } \\
\text { Suario Menendiz (8) }\end{array}$ \\
\hline $\begin{array}{l}\text { 10.- Sempronio, padre de } \\
\text { Sesgudo Semproniz, presbiter } \\
\text { (14). }\end{array}$ & $\begin{array}{l}\text { 11.- Godesteo Suariz, hijo de } \\
\text { Suario Menendiz (8). }\end{array}$ & 12.- Ruderico. \\
\hline $\begin{array}{l}\text { 13.- Elias Gelmiriz, hermano } \\
\text { de Leouili Gelmiriz, juiz (22). }\end{array}$ & $\begin{array}{l}\text { 14.-Sesgudo Semproniz, } \\
\text { presbiter, hijo de Sempronio } \\
\text { (4). }\end{array}$ & $\begin{array}{l}\text { 15.- Sesgudo Sospodemiriz, } \\
\text { presbiter, compró a Menendo } \\
\text { Baltariz (16) y a Sescuto pres- } \\
\text { biter de Fortuno (17). }\end{array}$ \\
\hline $\begin{array}{l}\text { 16.- Menendo Baltariz, ven- } \\
\text { dió a Sesgudo presbiter Sos- } \\
\text { podemiriz (15). }\end{array}$ & $\begin{array}{l}\text { 17.- Sescuto, presbiter de } \\
\text { Fortuno, vendió a Sesgudo } \\
\text { Sospodemiriz, presbiter (15). }\end{array}$ & $\begin{array}{l}\text { 18.- Sescuto, presbiter ¿El } \\
\text { mismo (17)?. }\end{array}$ \\
\hline 19.- Leouilli Ioacinz. & $\begin{array}{l}\text { 20.- María, vendió a Leouili } \\
\text { Gelmiriz, juiz (22). }\end{array}$ & $\begin{array}{l}\text { 21.- Rodosiui, vendió a } \\
\text { Leouili Gelmiriz, juiz (22). }\end{array}$ \\
\hline $\begin{array}{l}\text { 22.- Leouili Gelmiriz juiz, } \\
\text { hermano de Elías Gelmiriz } \\
\text { (13), compró a Maria (20) y a } \\
\text { Rodisiui (21). }\end{array}$ & 23.- Uimarrara. & 24.- Gonza Adaquiz. \\
\hline 25.- Adosinda Diaz. & 26.- Abbas Pelagius qui notuit. & \\
\hline
\end{tabular}

Tabla 2

Personas que intervienen en la donación a Santa Leocadia de Guillade 
De los datos obtenidos se deduce que entre los otorgantes de la donación existen abundantes relaciones de parentesco que seguramente irán más allá de lo que nombres, patronímicos y renombres permiten comprobar. Asimismo, esta pequeña comunidad rural interactúa comprándose unos a otros diversas piezas de terreno. La presencia del juez Leouili Gelmiriz y de distintos presbíteros hace pensar en una sociedad jerarquizada, tanto en lo religioso como en el plano civil.

Antes de abordar la exposición de los bienes donados, es preciso subrayar la dificultad que entraña asociar debidamente los diversos bienes con sus respectivos donantes. La enrevesada redacción del documento no permite atribuir con demasiada claridad qué es lo que entrega cada donante, pues en ocasiones no se sabe dónde acaba lo que dona una persona y dónde empieza lo que dona la otra. Una solución hubiera sido transcribir en bloque todo el dispositivo documental, o bien correr el riesgo de introducir puntos y comas: esto es lo que se ha hecho para facilitar la lectura del texto.

Lo primero que se observa es el proceso de desintegración de las antiguas villae -en este caso la de Guillade- las cuales en un pasado más o menos remoto hubieran comprendido varios casales.

Ahora, los sucesivos repartos hereditarios afectan ya a los casales: la unidad del antiguo casal de Metato, rota en el año 963 en seis partes, parece que vuelve a unirse para ayudar al sostenimiento de la nueva iglesia; la mitad del casal de Linares, comprado por su dueño, se dona también; así como también la sexta parte de la mitad del casal de Sempronio.

Otras donaciones a Santa Leocadia permiten entrever ciertos aspectos agrarios: El presbítero Sesgudo Sospodemiriz dona la mitad del casal de Portezello y lo entrega con todo lo que tuviese tanto por compra como por ganancia -perfectos o mejoras obtenidas- así como cinco castaños en unos campos junto al riachuelo, a lo que añade isto libro místico, es decir un libro de contenido variado o misceláneo; igual hace el juiz Leouili Gelmiriz con sus quiñones íntegros en el casal de Uimarrara. Otras piezas menores también se donan a Santa Leocadia, como la quinta parte de las manzanas que allí hubiese de illo pumare.

La donación del presbítero Sescuto incluye, además de toda su heredad con casas, viñas, pumares y $\operatorname{sotos}^{27}$, la entrega de ajuar doméstico con todos los objetos de utilidad que deben hallarse en una buena casa, entre éllos tota perfia ${ }^{28}$

${ }^{27}$ En Galicia el soto o "souto" equivale a terreno con castaños.

${ }^{28}$ El Diccionario da Real Academia Galega define la voz "perfia" como "calquera recipiente para conter líquidos, como unha sella, unha cuba, un barril...": véase CONSELLERÍA DE EDUCACIÓN E ORDENACIÓN UNIVERSITARIA DE LA XUNTA DE GALICIA, Diccionarios de Galego, [En línea]. <http://www.edu.xunta.es/diccionarios/BuscaTermo.jsp> [Consulta: 01.05.2009]. 
-expresión que en otros documentos se dice porfia / porfías- y que equivale a copas, vasos o vasijas en general; arcas -es decir baúles, los antecesores de los actuales armarios-; un lagar - que acredita el cultivo consolidado de la vid-, mesas, cadeyras (cathedra=silla) y, lo que obliga considerar un relativo alto status social del donante, tres libros religiosos: un hordine perfecto, que puede interpretarse como un libro completo de liturgia local; otro que, al parecer, contiene la liturgia desde quadragesima, es decir, desde Cuaresma, hasta el dia de San Pedro, un salterio o libro de salmos, además de otros caros objetos: una campana de metal, un cáliz de plata y una cruz. A todo ello añade una prenda de vestir; diversas cabezas de ganado porcino, cuyas cualidades no es necesario explicar; ovino y caprino, fácil de mantener y de obvias utilidades: leche, queso y lana; además se incluyen, vacas y bueyes, proporcionando aquellas leche, queso y mantequilla, mientras que estos proporcionarían fuerza de tiro para labra de campos y transporte, sin olvidar el imprescindible fertilizante natural que proporcionarían; finalmente, colmenas, regalo nada desdeñable, ya que éstas suponen la disponibilidad de un nutritivo alimento, así como la obtención de cera para el alumbrado doméstico y litúrgico.

Otros bienes donados mencionan algunas partes del casal de Uimarrara y un quiñón en Uarcena. Y, desde luego, no podían faltar las lareas -en gallego leiras-, porciones de terreno cultivado, cinco en total y una rotea.

Concluyendo: todos los indicios llevan a pensar que Santa Leocadia es una iglesia, no un monasterio; que la iglesia se hace exnovo: la entrega de los libros litúrgicos, de la campana, del cáliz y de la cruz parecen los instrumentos básicos para que una iglesia empiece a desarrollar sus funciones. La dotación de bienes para el mantenimiento del sacerdote apoya la creación o fundación de la iglesia.

Los cinco presbíteros participarían junto a Pelagius abbas en la consagración de la nueva iglesia, en cuyo acto el juez Louili Gelmiriz ocuparía un lugar destacado. Seguidamente, bajo unos carballos próximos, lugar que en el futuro se llamará o campo da festa, los curas y los vecinos celebrarían el evento, quizá amenizado por un par de músicos populares de la comarca, y cada grupo o familia, según sus posibilidades, comería y bebería más o menos copiosamente. A partir de entonces, los toques de campana regularán la vida comunitaria.

Ante la nueva iglesia dos o tres olivos recién plantados irán creciendo y proporcionarán los santos óleos; las viñas de la iglesia permitirán la consagración del vino; a la sombra de los olivos los vecinos se reunirán para tomar acuerdos comunales, escuchar pregones, o establecer relaciones sociales a la salida de la misa; los nuevos vecinos bautizarán a su hijos... y en el atrio enterrarán a sus muertos.

Los vecinos de la villa de Guillade ya tienen su iglesia: son una comunidad definitivamente organizada. 


\section{Santa Leocadia de Guillade y el monasterio de Melón}

Antes de concluir puede preguntarse qué relación hubo entre Santa Leocadia y el monasterio de Santa María de Melón. No hay ningún dato directo que permita contestar. Únicamente pueden hacerse conjeturas sobre tres documentos: uno de la reina doña Urraca del 21 de enero de 1113, en el cual aquella vende a Pedro Ordóñez "mea hereditate que habeo in vila que vocitant Guilhadi pro pretio (...) id est, nominato $\mathrm{CCC}^{\text {os }}$ modios" ${ }^{29}$; y dos documentos de Alfonso IX: el primero otorgado en Zamora el 5 de febrero de 1205, por el cual dona a domno Suero Díaz "illud meum regalengum de Guillady cum suis cautis et pertinenciis suis iure hereditario" ${ }^{30}$; y el otro, con el que el mismo rey confirmará, en Benavente -a 2 de octubre de $1228^{31}$-, al mismo domno Suero Díaz la donación ya mencionada. De todo esto, y a la vista de las propiedades que el monasterio de Melón tiene en Guillade y sus alrededores, sólo puede intuirse que los bienes citados en los tres documentos acabaron pasando a la propiedad de Santa María de Melón, sin que sea posible ahora establecer con detalle cómo se transmitieron a Melón aquellas propiedades. Acaso se perdieron los documentos acreditativos, si bien debe tenerse en cuenta que durante la Edad Media, cuando se hacía una transmisión de bienes, muchas veces bastaba con que el cedente entregase al cesionario los títulos de propiedad de los bienes cedidos. Este puede ser el caso, dado que los documentos ya reseñados -incluyendo el de la iglesia de Santa Leocadia- se hallan en poder del monasterio de Melón; además, el Tumbo 325 del AHN, desde el folio 268r., que se encabeza con cajon 38, Legajo 75. Guillade, Huma y Batallanes, incluye con el núm. 1 los dos documentos de Alfonso XI; a continuación del documento núm. 15, incluye sin número el documento de la Reina Urraca; e inmediatamente después de este, incluye con el núm. 16 el documento de Santa Leocadia. Esto quiere decir que el monasterio de Melón identificaba como suyos los bienes contenidos en dichas escrituras. Documentalmente se comprueba que posee bienes en Guillade, porque el monasterio los los irá aforando a diversos colonos ${ }^{32}$.

${ }^{29}$ AHN, Melón, 1437/5, es copia simple.

${ }^{30}$ Incluído en confirmación del mismo Alfonso IX otorgado en Benavente el 2 de octubre de 1228, AHN, Melón, 1440/18

${ }^{31} I d$. ib. La afirmación de Claudio González Pérez "y éste [Suero Didaci] se lo entregó al monasterio de Melón" no se respalda documentalmente: véase Mariano PiñEIro GroBA, Claudio GonZÁlez Pérez, Historia de Puenteareas, Puenteareas, Centro Cultural Municipal, 1983, pág. 66.

32 Dentro del apartado referido a Guillade, Huma y Batallanes, se localizan los siguientes foros: año 1233, fol. 269r., foro del monasterio de Melón en "la aldea de Guillade"; año 1264, mismo folio, foro en el casal de de Palacios; año 1269, fol. 269v., foro en Pazos de Guillade; año 1309, fol. 270r., foro en San Miguel de Guillade. 
Un indicio relativo a las supuestas transmisiones patrimoniales a Melón podría ser una escueta noticia en un interesante pleito de Melón con la villa de Salvatierra en el año 1384 sobre los pedidos y pechos reales, en la que un testigo declara que "preguntado por las casas que o dito moesteiro ha en Guillade u chaman Pazos, respondeu et disso, que en o dito lugar de Pazos, que sabia que tinna unha casa benfeitada, et que sabia que fora dun cabaleiro, et que morrera y, et que la mandara a o dito moesteiro de Melon..." ${ }^{33}$.

$* * * * * * *$

Estas páginas finalizan reiterando la reflexión del comienzo: la indigencia y precariedad de la historiografía gallega en lo relativo al abúlico estado de publicación de fuentes: un lastre que imposibilita un mayor conocimiento de nuestro pasado: interpretaciones erróneas, o a la ligera, inexactitudes o logomaquias más o menos contrastadas -aquí se han visto algunas- se repiten sucesivamente con el sólo argumento de "autoridad". A esta situación contribuye la cada vez más paupérrima formación de las nuevas generaciones de historiadores, sin conocimientos de latín, de historia de la Iglesia, de la Filosofía e incluso de la propia crítica documental, que provoca inexorablemente dificultades de interpretación. Por ello, innovemos perfeccionando disciplinas útiles, no desechándolas; en eso consiste el progreso, que muchos confunden, sin embargo, con "tradicionalismo" en la forma de hacer historia.

\section{Criterios de transcripción}

Se utilizan las normas habituales sobre abreviaturas y abreviaciones; además, debe tenerse en cuenta lo que sigue:

- La invocación se señala en mayúsculas (CHRISTUS).

- El fin de renglón en el original se indica con «I », y a continuación en superíndice el número de la nueva línea.

- Las frases o palabras escritas entre renglones se transcriben en letra normal entre $\backslash /$.

- La restitución cierta de lo escrito cuando hay una laguna en el texto se escribe entre corchetes [ ].

- Lagunas no restituíbles en el texto se indican con puntos suspensivos entre corchetes [...].

- Los caracteres no presentes en el texto, pero indispensables para su sentido se transcriben entre ángulos $<>$.

- $\mathrm{La}$ «u» se transcribe por «u» y las «V» por «V», independientemente del sentido textual.

- No se indican las palabras abreviadas.

${ }^{33}$ AHN, Fondo códices, Tumbo 325, fol. 276v. 


\section{Edición}

963, junio 24.

Los hombres de Guillade donan a la iglesia de Santa Leocadia diversas partes de heredades. Entre aquellos, el presbítero Sescudo dona cuatro libros, algunos enseres litúrgicos y otros bienes muebles.

Copia simple: AHN, Clero regular, Císter, pergaminos de Santa María de Melón, carpeta 1437, doc. núm. 1, 555x320 mm., minúscula diplomática imitativa de privilegios reales, último tercio del siglo XII, bien conservado excepto en algunas dobleces.- Del mismo archivo, Fondo códices, Tumbo 325, fols. 282r y v, y 283r, sobre el cual se toman las letras o palabras restituidas.AHPO, Fondo General. Tumbo de fray Lorenzo Pérez, de Melón, año 1611, Clero, Libro 339, Melón, fol. 337r.

Edita sobre el Tumbo 325: Jesús FerRo Couselo, Los petroglifos de término y las insculturas rupestres de Galicia, Orense, Talleres gráficos de Miguel López Elizalde, 1952, doc. 15, págs. 220-221.

Edita parcialmete y traduce sobre el anterior Xoán MARTíneZ do TAMUXe, "Documento medieval. Pista arqueológica de un monasterio", Tuy, Museo y Archivo Histórico Diocesano, 3 (1977), págs. 70 y 71.

Cita sobre Ferro Couselo José Filgueira Valverde y Alfredo García Alén, Materiales para la carta arqueológica de la Provincia de Pontevedra, Pontevedra, Museo, 1953, pág. 51.

Cita sobre Ferro Couselo M. Rubén García Álvarez, "Los libros en la documentación gallega de la Alta Edad Media", Cuadernos de Estudios Gallegos, 20, fasc. 62 (1965), pág. 24.

Cita sobre Ferro Couselo y García Álvarez Manuel C. DíAZ y DíAz, Códices visigóticos en la monarquía leonesa, León, Centro de Estudios e Investigación San Isidoro, 1983 (Col. Fuentes y Estudios de Historia Leonesa, 31), pág. 168 y n. 55.

Cita sobre el anterior Manuel LuCAS ÁlvAREz, "Paleografía gallega. Estado de la cuestión", Anuario de Estudios Medievales, 21 (1991), pág. 431 y n. 29, refiriéndose al doc. fechado en 963-06-24.

CHRISTUS. $-\left.\right|^{1}$ Domnis hac inuictissimis hac triumphatoribus Sanctisque Martiribus, Sancti Saluatoris et Sancta Maria semperque uirginis, Sancta Leocadia et Sancta Eolalia, et Sancti Mametis, et Sancti Facundi et Primitiui, et Sancti Isidori episcopi, cuius domus et baselica fundata $\mathrm{l}^{2}$ est territorio sedis tudense, loco predicto uilla quos uocitant Quillati, subtus monte Castrello, discurrente ribulo Huma. 
Nos, homines, qui subter scriptura uel sine facturi, sumus qui testamus et concedimus nostras hereditates $\left.\right|^{\beta}$ ad domus ipsius Sancti iam superius nominati. Et nos, hic nominati, sumus:

In primis, Menindo presbiter dono et concedo omnia mea hereditate quanta habeo de habiorum parentorum meorum in kasal de Metato, de medietate, VI ${ }^{\mathrm{a}}$ integra. Planzenzo presbiter $\left.\right|^{4} \mathrm{VI}^{\mathrm{a}}$ in kasal de Metato. De hereditate de Zacharias, de suo iermano Vimara presbiterum, hic in illo kasal de Metato $\mathrm{VI}^{\mathrm{a}}$ integra. De Helias Zacharias hic in illo kasali de Metato $\mathrm{VI}^{\mathrm{a}}$ integra qui comparauit Vimara presbiterum. De Senorina Adulfici VI ${ }^{\mathrm{a}}$ integra $\mathrm{I}^{5}$ hic in kasal de Metato. Hic in kasal de Metato quinione de Adaulfo integro, de $\mathrm{VI}^{\mathrm{a}}$, quarta. Quinione de Suario Menendiz $\mathrm{h}$ [ic in] kasal de Metato ab integro VI ${ }^{\mathrm{a}}$, de kasal de Linares conpara de Tiuili Benedictiz medietate integra. In Lamella de kasal Sempronio, ${ }^{6}$ de medietate, $\mathrm{VI}^{\mathrm{a}}$. Quinione de Suario Menendiz integra, de suo iermano Godesteo Suariz alia VI integra; De quinione de Ruderico, medietate de Gontina integra. Kasa de Elias Gelmiriz integro. De Sesgudo presbiterum connomento Semproniz sua porl ${ }^{7}$ tione que habeo de aviorum meorum siue de comparatea quomodo de ganancia. De Sesgudo presbiterum, connomento Sospodemiriz, kasal de P[orte]z[e]lo siue de comparatea quomodo de ganancia, extra tres lareas cum suo planctato, una in Milaqueto et alia de parte illo riu in Fondon $1^{8}$ et alia in illa Uarcena, quinione que comparauit de Menendo Baltariz cum alia de suo patre qui testamus ad illo loco de Sancti Thome de [illa her]rmida, et ibi damus $\mathrm{V}^{\mathrm{a}}$ de illo pumare de illa mazana que ibi abuerit et $\mathrm{V}^{\mathrm{e}}$ kastinarios in campos de surrsum in illo rego $\mathrm{I}^{9}$ et isto libro mistico per sic qui ibi testamus, et illa rotea da Bocalosa ad Sancta Leocadia, larea de Agro Plana que comparauit de $\mathrm{Se}$ [sc]uto presbiterum de Fortuno; et ego Sescuto presbiterum testo et concedo ad ipsius Sancta Leocadia omnia mea rem hereditatem cum kasas, cum $1^{10}$ uineas, cum pumares, cum sautos cum omnibus adiuntionibus que ad prestitum hominis est, imptus et foris, cubus, cu[pas], a[rch]as, $\mathrm{I}^{\circ}$ lagare, mensas, cadeyras, tota perfia qui est continentia de bona kasa que a prestitum est, duos libros: $\mathrm{I}^{\mathrm{o}}$ hordino perfecto $\left.\right|^{11}$ et alio libro de $\mathrm{X}^{\mathrm{L}^{\mathrm{a}}}$ usque ad diem Sancti Petri, $\mathrm{I}^{\mathrm{o}}$ psalteiro, [unum sign] um de methallo, $\mathrm{I}^{\circ}$ kalice de argento et $\mathrm{I}^{\mathrm{a}}$ cruce, [cape]llo de li]no, porcos, porcas, kabras, ouelias, boues, uachas, colmenas, omnia rem cuncta que habeo do et concedo ad domus Sancta Leocadia ${ }^{12}$ pro remedium anime mee et ad qui ibidem uita sancta perseuerauerit. Et qu[i] testauit Leouilli Ioazinz larea de Requieiso integra. [Alia leira de] Maria et de Rodosiui que compara Leouili Gelmiriz juiz [suos] quiniones integros in kasal de Uimarrara, et in Uarcena de Liul ${ }^{13}$ uanes suo quinione. Duas lareas de Gonza Adaquiz, $\mathrm{I}^{\mathrm{a}}$ in Paretes et alia in illa Costa Plano. Et alia larea de Gota in Nouales de Ripa in ripa medietatem et alio quinione de Adosinda Diaz integro que ex parte per isso ribulo. 
${ }^{14}$ Ipsas hereditates iacent et abent termino de Porto de Aluelli usque fere se in pena de Undurina et expartent per aqua de Sancgineiro usque in Ruburdino et inde ad Mamola Longa, et expartent per fonte de Beteiro usque fere in illo Soverario de Sixti et fingent se $\mathrm{I}^{15}$ in illa divisione de Quilliara usque in Petra Burgata.

Nos autem testamus et concedimus pro remedium animas nostras a domus Sancta Leocadia [et] ad qui ibidem uita sancta perseveraverit.

Et si aliquis homo uenerit qui hunc factum nostrum irumperit et illas hereditates inquie ${ }^{15}$ tare, post parte de ipsius Sancti, sit sedeant excomunicatos \asque/ adnatema sit, et illas hereditates dublatas, et a parti regi uel Domini Imperatore terre D solidos, et uos perpetim habitura.

Factum seriem testamenti sub die erit VIII ${ }^{\circ}$ kalendas iullias, era M. ${ }^{a}$ prima. Abbas Pelagius qui notuit.

\section{Topónimos mencionados ${ }^{34}$}

Agro Plana, leira de.

Beteiro, fonte de, [término de Porto de Alvelli].

Bocalosa, rotea da.- Parroquia de San Miguel de Guillade. Prov. de Pontevedra. Concello de Ponteareas.

Castrello, monte.- Próximo a la parroquia de San Miguel de Guillade. Prov. de Pontevedra. Concello de Ponteareas.

Costa Plano, villa, [término de Porto de Alvelli].

Fondon.- No límite da parroquia de San Miguel de Guillade con Santo André de Uma. Prov. de Pontevedra. Concello de Ponteareas.

\footnotetext{
${ }^{34}$ Como es habitual, se ha consultado para las identificaciones toponímicas el Nomenclátor de Galicia. Toponimia oficial das provincias, concellos, parroquias e lugares, [CD ROM], [s.1.], Xunta de Galicia, [d.1. 2004], además de las cartografías de Andrés PreCEDo Ledo y José SANCho Comíns (dir.), Atlas de Galicia, vol. I: Medio Natural, [Santiago de Compostela], Sociedade para o Desenvolvemento Comarcal de Galicia, 2001; Andrés Precedo Ledo y Manuel Gallego Priego (dir.), Mapa de límites das parroquias. Cartografía territorial básica de Galicia, [Santiago de Compostela], Sociedade para o Desenvolvemento Comarcal de Galicia, 2001; y la herramientas web cartográficas de la CONSELLERÍA DO MEDIO RURAL DE LA XUNTA DE GALICIA, Visor SixPac del Fondo de Garantía Agraria (FOGGA), [En línea]. <http://emediorural.xunta.es/visor5/> [Consulta: 01.05.2009], así como las digitalizaciones del Catastro del Marqués de la Ensena (1753), disponibles en MINISTERIO DE CULTURA, Portal de Archivos Españoles (PARES), [En línea]. $<$ http://pares.mcu.es/Catastro/> [Consulta: 01.05.2009]. Finalmente, han resultado de especial interés las informaciones toponímicas contenidas en el ya citado artículo de Xoán MARTínEZ do TAMUXE, "Documento medieval. Pista arqueológica...", págs. 77-78 que dan cuenta, como tantas otras veces, de las carencias de los nomencátores oficales, más atentos a criterios político-filológicos que a la realidad histórica identitaria.

En ocasiones resulta dificultoso diferenciar entre topónimos y nombres que se refieren a propietarios; lo mismo sucede con algunas denominaciones de terrenos.
} 
Guillade, San Miguel de.- (villa Quillati).- Parroquia.- Prov. de Pontevedra. Concello de Ponteareas.

Huma, ribulo, v. UMA, río.

Lamela, A, lugar de.- (Lamella).- Parroquia de San Cibrán de Mouriscados. Prov. de Pontevedra. Concello de Mondariz ${ }^{35}$.

Lamella, p. LAMELA, A.

Linares, kasal de.

Mamola Longa, [término de Porto de Alvelli].

Metato, kasal de.- Lugar da parroquia de Santo André de Uma. Prov. de Pontevedra. Concello de Salvaterra de Miño.

Milaqueto.

Nouales de Ripa, [término de Porto de Alvelli].- Lugar de Novás, na parroquia de San Miguel de Guillade. Prov. de Pontevedra. Concello de Ponteareas.

P[orte]z[e]lo, casal de.- Parroquia de San Miguel de Guillade. Prov. de Pontevedra. Concello de Ponteareas.

PAREDES, lugar de.- (Paretes).- Parroquia de San Lourenzo de Oliveira. Prov. de Pontevedra. Concello de Ponteareas ${ }^{36}$.

Paretes, [término de Porto de Alvelli], v. PAREDES.

Petra Burgata, [término de Porto de Alvelli].

Porto de Aluelli, término de.- Lugar de Albelle, na parroquia de San Miguel de Guillade. Prov. de Pontevedra. Concello de Ponteareas.

Quillati, villa, v. GuILLADE.

Quilliara, [término de Porto de Alvelli].

Requeixo, O, lugar de.- (leira de Requieiso).- Parroquia de San Fins de Celeiros. Prov. de Pontevedra. Concello de Ponteareas.

Requieiso, leira de, [término de Porto de Alvelli], v. ReQueIXo, O.

Ruburdino, [término de Porto de Alvelli].- Lugar de Rebordiño, no límite da parroquia de San Miguel de Guillade con Santo André de Uma. Prov. de Pontevedra. Concello de Ponteareas.

Sancgineiro, aqua de, [término de Porto de Alvelli].

Sancta Leocadia, v. SANTA LocAIA.

Sancti Thome.- No Catastro de Ensenada figura a Capela de Santo Tomé como linde da parroquia de San Miguel de Guillade coas de Santo Estevo de Cumiar e San Cibrán de Mouriscados. Prov. de Pontevedra. Concello de Ponteareas ${ }^{37}$.

\footnotetext{
${ }^{35}$ Xoán MarTínez do TAMUXe, “Documento medieval. Pista arqueológica...”, pág. 77, lo situa en San Miguel de Guillade.

${ }^{36}$ Id. ib., pág. 78.

${ }^{37}$ Podría tratarse de otra ermita de origen medieval; merecería un estudio arqueológico-histórico. Todavía existía en 1753.
} 
Santa Locaia, lugar de.- (Sancta Leocadia).- Parroquia de San Miguel de Guillade. Prov. de Pontevedra. Concello de Ponteareas ${ }^{38}$.

Sempronio, kasal de.- P. no lugar de A Lamela da parroquia de San Cibrán de Mouriscados. Prov. de Pontevedra. Concello de Mondariz.

Soverario, [término de Porto de Alvelli].

Uarcena de Liuuanes, [término de Porto de Alvelli].- Lugar de Louváns na parroquia de San Miguel de Guillade. Prov. de Pontevedra. Concello de Ponteareas.

Uarcena.

Uimarrara, kasal de [término de Porto de Alvelli].

UMA, río.- (ribulo Huma).- Afluinte do río Tea, que discorre polo condello de Ponteareas e pola parroquia de Santo André de Uma do de Salvaterra de Miño.

Undurina, pena de, [término de Porto de Alvelli].

\section{Personas mencionadas}

Adaulfo.

Adosinda Diaz.

Elias Gelmiriz.

Fortuno.

Godesteo Suariz, hermano de Suario

Menendiz.

Gontina.

Gonza Adaquiz.

Gota.

Helias Zacharias.

Leouili Gelmiriz, juez.

Leouilli Ioazinz.

Maria.

Menendo Baltariz.

Menindo, presbítero.
Pelagius, Abbas.

Planzenzo, presbítero.

Rodosiui.

Ruderico.

$\mathrm{Se}[\mathrm{sc}]$ uto, presbítero de Fortuno.

Senorina Adulfici.

Sesgudo connomento Sospodemiriz, presbítero.

Sesgudo, connomento Semproniz, presbítero.

Sixti.

Suario Menendiz, hermano de Godesteo Suariz. Tiuili Benedictiz.

Vimara, presbítero, hermano de Zacharias.

Zacharias, hermano de Vimara, presbítero.

${ }^{38}$ El Catastro del Marqués de la Ensenada menciona el "marco de Santa Leocadia" en uno de los lindes de la parroquia de Santiago de Oliveira; se supone que se refiere al linde con la parroquia de San Miguel de Guillade. Xoán Martínez do Tamuxe señala que el yacimiento de Castromao -muy próximo a los restos de Santa Leocadia- "pertenece, en parte, a Oliveira (Santiago). Pues suponemos que antiguamente haya pertenecido, tanto este «castro» [Castromao], como el poblado, que vamos a estudiar [Santa Leocadia], íntegramente a Guillade": véase, respectivamente, MINISTERIO DE CULTURA, Portal de Archivos Españoles (PARES), [En línea]. <http://pares.mcu.es/Catastro/> [Consulta: 01.05.2009] y Xoán MARTínEZ Do TAMUXE, "Documento medieval. Pista arqueológica...”, pág. 63. 


\section{Palabras en Romance}

aqua de Sancgineiro
cadeyras
colmenas
cruce
duos libros
fonte de Beteiro
hordino perfecto
isso
juiz
kalice

larea de Requieiso

libro mistico

Mazana

ouelias

pena de Undurina

psalteiro

Rego

rotea da Bocalosa

uachas

pena de undurina 